\title{
Quality of Life and Safety Outcomes Following Irreversible Electroporation Treatment for Prostate Cancer: Results from a Phase I-Ii Study
}

Van den Bos $W^{1 *}$, De Bruin DM ${ }^{1,2}$, Veelo DP ${ }^{3}$, Postema AW ${ }^{1}$, Muller BG ${ }^{1}$, Varkarakis IM ${ }^{4}$, Skolarikos A, Zondervan PJ1, Laguna Pes MP1, SavciHeijink CD ${ }^{5}$, Wijkstra $\mathrm{H}^{1,6}$, De Reijke TM ${ }^{1}$ and De La Rosette $\mathrm{JJMCH}^{1}$

${ }^{1}$ Department of Urology, Academic Medical Center, University of Amsterdam, The Netherlands

${ }^{2}$ Department of Biomedical Engineering \& Physics, Academic Medical Center, University of Amsterdam, The Netherlands

${ }^{3}$ Department of Anaesthesiology, Academic Medical Center, University of Amsterdam, The Netherlands

${ }^{4}$ Department of Urology, Athens Medical University, University of Athens, Greece

${ }^{5}$ Department of Pathology, Academic Medical Center, University of Amsterdam, The Netherlands

${ }^{6}$ Department of Electrical Engineering, Eindhoven University of Technology, The Netherlands

\begin{abstract}
Objective: Prostate cancer treatment as radical prostatectomy or radiation therapy is associated with collateral tissue damage resulting inside-effects. Irreversible electroporation is a minimally invasive technique that has shown to be effective in destroying tumour cells and has been proposed to diminish the treatment related morbidity. The aim of the study was to evaluate the safety and quality of life (QoL) and functional outcomes of extended and focal irreversible electroporation (IRE) in prostate cancer.
\end{abstract}

Methods: IRE-ablations of the prostate were performed using two treatment protocols (focal and extended) to assess potential variation in outcomes. The safety of IRE was assessed by the device-related, periprocedural- and post procedural adverse events. Post-procedural quality of life was measured by prostate cancer-specific QoL questionnaires. Several validated questionnaires were used to determine the following outcomes: genitourinary side effects, urinary and erectile function. Post-procedural pain was scored using the visual analogue scale and the length of hospital stay was documented.

Results: Mainly mild adverse events (grade 1-2) occurred during the short-term follow-up, mostly concerning lower urinary tract symptoms. Nearly all resolved between the first and fourth week post treatment. Quality of life assessment showed deterioration in the urinary domain for both treatment protocols. Functional outcome questionnaire results remained stable over time. The reported post-procedural pain was low with a median of 0.5 one day post-IRE, and the length of hospital stay was short (mean of 3 days). Analysis per treatment protocol showed a significant increase between one and four weeks post treatment $(p=0.03)$ in the extended treatment group.

Conclusion: Irreversible electroporation can be performed safely in patients suffering from prostate cancer. The adverse events are mostly temporary. Quality of life assessment shows deterioration in the urinary domain; however, functional outcomes remain stable over time.

Keywords: Prostate cancer; Irreversible electroporation; IRE; Safety; Quality of life; Side-effects; Focal therapy

Abbreviations: HIFU: High-Intensity Focused Ultrasound; CRYO: Cryotherapy; NR: Not Reported

\section{Introduction}

Prostate cancer (Pca) was the second leading cause of male cancer death in 2014, representing $27 \%$ of the total number of new cancers [1]. Pca is currently often diagnosed at an earlier stage because of prostatespecific antigen (PSA) testing, extended prostate biopsies and improved imaging techniques $[2,3]$. Most patients are now being diagnosed with low- and intermediate risk organ-confined disease [4]. These stages of Pca commonly stay symptomless and may remain non-mortal [5]. Nevertheless, the fear and uncertainty of suffering from cancer are often a motive to choose active treatment over active surveillance [6,7]. Active treatments as radical prostatectomy or radiation therapy are associated with collateral tissue damage causing morbidity including urinary incontinence (0-20\%), bowel problems (22-36\%) and erectile dysfunction (19-74\%) [8-10]. Therefore, several minimally invasive techniques have been proposed to diminish the collateral damage and to spare the urinary sphincter, rectum and neurovascular bundles. The purpose of these so-called focal therapies (FT) is to reduce side-effects without jeopardising the oncological outcomes [11].

Irreversible electroporation (IRE) is a new ablative technique using high-voltage low energy electric pulses to destroy cells by creating persistent micropores. If the IRE procedure is properly executed, essential structures as the urethra, neurovascular bundles and the rectum may stay unharmed potentially lowering post procedural sideeffects $[12,13]$. In recent years, interest in IRE as an ablation modality has grown and studies on IRE have been increasingly reported in

*Corresponding author: Van den Bos W, Academic Medical Center, University of Amsterdam Meibergdreef 9, 1105 AZ Amsterdam, The Netherlands, Tel: 3150566 6465; E-mail:w.vandenbos@amc.uva.nl

Received September 02, 2015; Accepted October 17, 2015; Published October 24, 2015

Citation: den Bos WV, Bruin DMD, Veelo DP, Postema AW, Muller BG, et al. (2015) Quality of Life and Safety Outcomes Following Irreversible Electroporation Treatment for Prostate Cancer: Results from a Phase I-li Study. J Cancer Sci Ther 7: 312-321. doi:10.4172/1948-5956.1000369

Copyright: (c) 2015 den Bos WV, et al. This is an open-access article distributed under the terms of the Creative Commons Attribution License, which permits unrestricted use, distribution, and reproduction in any medium, provided the original author and source are credited. 
Citation: Bos WVden, Bruin DMD, Veelo DP, Postema AW, Muller BG, et al. (2015) Quality of Life and Safety Outcomes Following Irreversible Electroporation Treatment for Prostate Cancer: Results from a Phase I-li Study. J Cancer Sci Ther 7: 312-321. doi:10.4172/19485956.1000369

the literature [14]. However, data on safety, pain, adverse events and functional outcomes has not yet been published in literature. This study aims to evaluate the safety and quality of life outcomes of extended and focal irreversible electroporation (IRE) in Pca.

This registered (NCT001790451) phase I/II, prospective, twoarm interventional, multicentre study was approved by local Ethics Committees within the European Union.

The study protocol (including in- and exclusion criteria) has been described elsewhere in detail [15].

\section{Materials and Methods}

\section{Study design and conduct}

Patients with histopathologically Pca, scheduled for a radical prostatectomy as their primary treatment, were invited to participate in the study. The inclusion criteria were patients who were indicated to undergo a radical prostatectomy and a life expectancy of more than 10 years without prostate calcifications greater than $5 \mathrm{~mm}$. All patients underwent an electrocardiogram evaluation to rule out cardiac rhythm disorders. Informed consent was obtained from all patients after detailed explanation and carefully discussing the potential risks of the trial. Recruitment took place during 2013 and 2014 in two university hospitals (Academic Medical Center, Amsterdam and Sismanoglio general hospital, Athens). The institutional review boards of the two participating institutions in The Netherlands and Greece approved the study.

The primary objective was to determine if the IRE ablation procedure is safe as measured by the total number of device-related, periprocedural- and postprocedural adverse events. The treatmentrelated toxicity was graded by the NCI Common Terminology Criteria for Adverse Events (CTCAE) Version 4. CTCAE is widely accepted throughout the oncology research community as the standard grading scale for adverse events (AE). The grade refers to the severity of the AE. All complications were recorded prospectively by the participating centers. A serious adverse event (SAE) was defined as any untoward medical occurrence that requires inpatient hospitalization or prolongation of it, results in persistent or significant disability/ incapacity, is life threatening, or results in death.

The secondary objective was to determine quality of life (QoL) as measured by Expanded Prostate Cancer Index Composite (EPIC) and the IPSS Quality of Life score (IPSS-QoL). The EPIC is a validated comprehensive instrument designed to evaluate function and bother after Pca treatment, assessing patients' urinary, bowel, sexual and hormonal status [16]. Furthermore, post-procedural pain was scored using the visual analogue scale (VAS), at four hours after the procedure, the morning after the procedure and during the planned follow-up visits. Perioperative outcomes and length of hospital stay were documented. Genitourinary side effects were assessed by the following validated questionnaires: the five-item version of the International Index of Erectile Function (IIEF-5), International Prostate Symptom Score (IPSS) and, if required, time of indwelling catheter. The IPSS is based on answers to seven questions concerning urinary symptoms with one additional question concerning quality of life. The total score can therefore range from 0 to 35 (asymptomatic to very symptomatic). The quality of life due to urinary symptom score ranges from 0 to 6 (delighted to terrible). The IIEF- 5 is the shortened and simplified version of the International Index of Erectile Function questionnaire (IIEF) and is a validated, widely used questionnaire with high levels of specificity and sensitivity to erectile dysfunction [17].
The questionnaires were administered during visits before the IRE procedure, one week, and four weeks after the procedure. Furthermore, uroflowmetry was also acquired to determine the quality of voiding.

\section{IRE-treatment}

Patients were admitted the day before the IRE procedure and were asked to complete all quality of life, functional and pain-related questionnaires. The IRE treatment was performed using the NanoKnife (AngioDynamics, Queensbury, NY, USA). The technique utilizes high-voltage microsecond electrical pulses, applied through 19-gauge monopolar needle electrodes leading to the formation of nanopores in the cellular membrane $[18,19]$. Due to the increased cell membrane permeability and subsequent in- and efflux of ions, a destabilization of the existing cellular transmembrane potential is caused. The cell loses its homeostatic properties resulting in cell death [20-22]. Patients received prophylactic antibiotics two hours preoperatively and general anaesthesia with propofol and/or sevoflurane, sufentanil was induced. After positioning the patients in extended lithotomy position, a transurethral $18 \mathrm{Ch}$ catheter was inserted. The IRE electrodes were transperineally inserted under ultrasound guidance. Prior to the start of pulsing, full paralysis was induced with a rocuronium bolus to prevent patient motion and associated risks. Neuromuscular monitoring was done with a TOF-watch SX acceleromyograph (MSD BV, Haarlem, The Netherlands) aiming for a train-of-four of zero counts and a post-tetanic count of 1-2 twitches during pulsing. To eliminate the risk of pulse-induced cardiac arrhythmias, an EKG-trigger monitor (Accusync, Milford, Connecticut, USA) was connected to a five-lead EKG to deliver the pulses synchronized with the refractory period of the heart. Ninety pulses were induced between each electrode pair, with the duration of 90 microseconds per pulse delivering an electric field of $1500 \mathrm{~V} / \mathrm{cm}$. The active length exposure was set at $1.5 \mathrm{~cm}$. Voltages were adapted following the first 20 pulses if resulting amps were below 20 or above $40 \mathrm{~A}$. Two treatment scenarios were used to assess potential variation in outcomes. Ablation in one lobe of the prostate using $\leq 3$ IRE electrodes was defined as focal. Ablation using 4-6 IRE needles in one of both lobes was called extended.

\section{Follow-up}

During the perioperative period and the 4-weeks between the IRE procedure and the RP, complications were documented per type and scored according to the CTCAE. The patient was discharged if successful voiding without significant residuals. In case of urinary retention, an indwelling catheter was reinserted and removed one week later during planned follow-up at the outpatient clinic. A visit at the outpatient clinic was scheduled one week and four weeks after the procedure and a telephone consultation at two weeks post-IRE.

\section{Statistical considerations}

The Wilcoxon signed rank test was used to evaluate differences between the nonparametric data of the questionnaire scores between the paired samples, measured at baseline and at each follow-up visit. Box plot graphics were computed to describe the outcomes over the follow-up period. Statistical significance was set at $\mathrm{p}<0.05$ and all tests were performed using IBM SPSS statistics, version 14.8.1.

\section{Results}

Sixteen patients were included from August 2013 to April 2014 and treated across the two centres, Academic Medical Center Amsterdam $(\mathrm{n}=12)$ and Sismanoglio hospital Athens $(\mathrm{n}=4)$. Patient characteristics 
Citation: Bos WVden, Bruin DMD, Veelo DP, Postema AW, Muller BG, et al. (2015) Quality of Life and Safety Outcomes Following Irreversible Electroporation Treatment for Prostate Cancer: Results from a Phase I-li Study. J Cancer Sci Ther 7: 312-321. doi:10.4172/19485956.1000369

show a mean age of $60 \pm 10$ years; median PSA was $8 \mathrm{ng} / \mathrm{mL}$ (IQR=713). Ten patients underwent systematic 12-core transrectal biopsies and six patients were diagnosed following targeted or extended biopsies ranging from 13 to 24 cores. Patient characteristics are shown in Table 1.

\section{Periprocedural outcomes}

Table 2 summarizes the periprocedural outcomes. The total OR time (time patients were situated in the OR) was on average 104 minutes with a mean anaesthesia time of 81 minutes. The mean duration of the IRE-treatment was 13 minutes, ranging from 2.5 minutes to 27 minutes, depending on the number of inserted electrodes. The patients were normally discharged one day after the procedure resulting in a mean hospitalization time of 3 days. One patient stayed one extra night because of social reasons. All procedures were uneventful. No cardiac arrhythmias occurred during IRE. However, one patient needed an additional dose of rocuronium during the procedure because of severe muscular contractions. Seven patients underwent a focal ablation and nine patients underwent an extended ablation.

\section{Safety and complications during four weeks follow-up}

Adverse events: Mild hematuria was noted in 5 patients during the first week following ablation. In all patients, the hematuria resolved spontaneously after 1 to 27 days. No severe hematuria or clotting was observed and no additional treatment or intervention was needed. Two patients reported mild hematospermia, lasting one and thirty days, respectively. During the first week following the IRE-procedure mild (CTCAE grade 1) urinary complaints including: urgency, frequency, painful micturition, or occasional incontinence were observed in seven patients (44\%), although none required the use of pads. The miscellaneous grade 1 events included a small perineal swelling, inguinal lymphadenopathy, temporarily swollen testis without fever, bilateral shin pain and/or pain in the lower abdomen without evidence of a urinary tract infection. In seven patients (44\%), the urinary complaints were noted as grade 2 , because the urgency or frequency was limiting the activities of daily living or pads were used due to urge incontinence. One patient started pelvic floor training. Six of the 16 patients (37.5\%) developed a urinary retention one-day post-operative. An indwelling catheter was placed in five patients for the mean duration of 7 days (range 5-9). The remaining sixth patient needed self-catheterization for 6 days. Following the removal of the indwelling catheters, one patient needed self-catheterization for three additional days. One patient developed a urinary tract infection and was treated with oral antibiotics. Another patient experienced diarrhea including hematochezia lasting for two days post-operatively, likely caused by hemorrhoids with no direct relation to the procedure. Furthermore, no rectal toxicity was noted, especially no case of rectourethral fistula or evidence of rectal injury has been observed. One

\begin{tabular}{|c|c|}
\hline Patient characteristics & Value \\
\hline Age in years (mean \pm SD) & $60.1 \pm 9.7$ \\
\hline PSA in ng/mL (median; IQR) & $8(7-13)$ \\
\hline Prostate volume mL (mean \pm SD) & $39 \pm 12.7$ \\
\hline Number of cores taken (median; IQR) & $12(12-15)$ \\
\hline Number of positive cores (median; IQR) & $3(1-6)$ \\
\hline Gleason score & $\mathrm{n}=8$ \\
\hline $3+3$ & $\mathrm{n}=3$ \\
\hline $3+4$ & $\mathrm{n}=3$ \\
\hline $4+3$ & $\mathrm{n}=2$ \\
\hline $4+4$ & \\
\hline
\end{tabular}

Table 1: Patient characteristics.

\begin{tabular}{|c|c|}
\hline $\begin{array}{c}\text { Perioperative outcomes of IRE treatment } \\
\text { Total OR time (minutes) }\end{array}$ & $\begin{array}{c}\text { Mean-Range } \\
(65-140)\end{array}$ \\
\hline Total anesthetic time (min) & $81(40-97)$ \\
\hline IRE-treatment time (min) & $13(2.5-27)$ \\
\hline Total hospitalization time (admission to discharge; days) & $3(3-4)$ \\
\hline Number of electrodes used & \\
\hline 2 & $\mathrm{n}=1$ \\
\hline 3 & $\mathrm{n}=6$ \\
\hline 4 & $\mathrm{n}=8$ \\
\hline 6 & $\mathrm{n}=1$ \\
\hline Catheterization time (days) ( $\mathrm{n}=6)$ & $7(5-9)$ \\
\hline Table 2: Perioperative outcomes of IRE treatment.
\end{tabular}

patient developed a urinary tract infection, which was complicated by an urosepsis. This led to hospitalization for 6 days during which he was treated with intravenous antibiotics. No further complications during this admission were registered. None of the patients experienced lifethreatening consequences nor were urgent interventions under general anesthesia needed. Tables 3 and 4 summarizes the adverse events by grade, incidence and point in time following IRE.

Quality of life (EPIC, VAS, and IPSS QoL): Significant differences were observed in one domain of the EPIC questionnaire, measured before the procedure (baseline) and during follow-up: Quality of life concerning the urinary function decreased significantly $(p=0.01)$, between pre-IRE and both the follow-up time points. Quality of life concerning sexual function did not significantly decrease during follow-up, however a significant rise was observed between the first and fourth week after treatment. The quality of life concerning hormonal function and bowel habits did not change significantly following IRE. Mean IPSS quality of life score was 2 (mostly satisfied) at baseline, 3 (mixed feelings) one week postoperatively and returned eventually to mostly satisfied at four weeks following the procedure, showing a significant increase between one and four weeks in follow-up $(\mathrm{p}=0.02)$. The outcomes are demonstrated in Table 5 and in boxplots in Figure 1.

Prior to the procedure, none of the patients experienced any pain relating to their Pca. Four hours after the procedure, the median VAS-score was 1.5 with an interquartile range of 0 to 4.75 . The day after the procedure, the median VAS-score was 0.5 . The scores were significantly different compared to the pain assessment at baseline, both with $\mathrm{p}$-values of 0.01 . At the first follow-up visit after one week, the pain score returned to baseline with a mean pain-score of 0.4 , showing no significant differences. Overview of the pain scores is shown in boxplots in Figure 2.

Quality of life per treatment protocol: When analyzing the outcomes per treatment protocol (focal versus extended), decreases in the urinary domain of the EPIC with a significant p-value were observed in the extended ablation group between baseline and one and four weeks follow-up ( $p=0.02$ and $p=0.04$ resp.). In the focal ablation group, no significant differences were noted. In the sexual domain, a significant increase between one and four weeks post treatment was only observed $(\mathrm{p}=0.03)$ in the extended treatment group.

Urinary and erectile function (IPSS+IIEF-5+uroflowmetry): IPSS outcomes did not differ significantly between baseline, 1 week and 4 weeks postoperatively. Mean values were 11, 12 and 12, respectively. The erectile function determined by the IIEF- 5 demonstrated no significant difference between baseline and follow-up. Furthermore, uroflowmetry showed a mean maximal flow of $17.2 \mathrm{~mL} / \mathrm{sec}$ at baseline, followed by $14.1 \mathrm{~mL} / \mathrm{sec}$ at one week and $14.3 \mathrm{~mL} / \mathrm{sec}$ at four weeks. 
Citation: Bos WVden, Bruin DMD, Veelo DP, Postema AW, Muller BG, et al. (2015) Quality of Life and Safety Outcomes Following Irreversible Electroporation Treatment for Prostate Cancer: Results from a Phase I-li Study. J Cancer Sci Ther 7: 312-321. doi:10.4172/19485956.1000369

These values, as well as the measured residuals after voiding, were not statistically different between the respective observations. The data are demonstrated in boxplots in Figure 3.

Urinary and erectile function per treatment protocol: No differences were seen between the two treatment groups concerning the urinary or erectile functions except for the maximum flow of the focal ablation group. The flow (Qmax) of this patient group decreased significantly four weeks post-treatment compared to baseline $(\mathrm{p}=0.01)$, where it did not in the extended group. The data are shown Figure 3.

All statistical results are shown in Table 5.

\section{Discussion}

The present study on safety and quality of life shows that ablations using IRE, either focally or extended executed, can be performed safely. During the four weeks follow-up, mainly grade 1 and 2 AE occurred, mostly concerning lower urinary tract symptoms. Nearly all resolved between the first and fourth week post-IRE. One grade $3 \mathrm{AE}$ (urosepsis) required a readmission whereupon the patient recovered rapidly. This urosepsis was possibly induced by the required indwelling catheter and advanced age $(70 y)$ of the patient. However, urosepsis is an serious complication and the possible occurrence of urosepsis should be taken into account during IRE follow-up. The quality of life, urinary and erectile function outcomes stay stable over time during the short follow-up. The high pain scores, reported directly after the procedure, could be influenced by indwelling catheters, which occasionally lead to bladder contractions. The decrease of the quality of life measured by the EPIC (urinary domain) was significant in the extended ablation group and not in the focal group, suggesting that ablation using four of

\begin{tabular}{|c|c|c|}
\hline Grade & Description & $\begin{array}{c}\text { Number of } \\
\text { patients }\end{array}$ \\
\hline 1 & $\begin{array}{c}\text { Mild; asymptomatic or mild symptoms; clinical or } \\
\text { diagnostic observations only; intervention not indicated }\end{array}$ & $15 / 16(94 \%)$ \\
\hline 2 & $\begin{array}{c}\text { Moderate; minimal, local or noninvasive intervention } \\
\text { indicated; limiting age-appropriate instrumental activities } \\
\text { of daily living }\end{array}$ & $8 / 16(50 \%)$ \\
\hline 3 & $\begin{array}{c}\text { Severe or medically significant but not immediately } \\
\text { life-threatening; hospitalization or prolongation of } \\
\text { hospitalization indicated; disabling; limiting self-care } \\
\text { activities of daily living }\end{array}$ & $1 / 16(6 \%)$ \\
\hline 4 & $\begin{array}{c}\text { Life-threatening consequences; urgent intervention } \\
\text { indicated }\end{array}$ & 0 \\
\hline 5 & Death related to AE & 0 \\
\hline
\end{tabular}

Table 3: Treatment-related toxicity according to CTCAEv4.0.

\begin{tabular}{|c|c|c|c|c|}
\hline & & Week 1 & Week 2 & Week 4 \\
\hline Grade 1 & $\begin{array}{c}\text { Haematuria } \\
\text { Painful micturition } \\
\text { Hematospermia } \\
\text { Pelvic pain } \\
\text { Urgency complaints } \\
\text { Frequency complaints } \\
\text { Miscellaneous }\end{array}$ & $\begin{array}{l}n=5 \\
n=2 \\
n=2 \\
n=1 \\
n=2 \\
n=2 \\
n=4\end{array}$ & $\begin{array}{l}n=5 \\
n=1 \\
n=2 \\
n=3\end{array}$ & $\begin{array}{l}n=4 \\
n=1 \\
n=1 \\
n=2\end{array}$ \\
\hline Grade 2 & $\begin{array}{l}\text { Urine incontinence } \\
\text { Urinary retention } \\
\text { Urinary tract infection } \\
\text { Urgency complaints } \\
\text { Frequency complaints } \\
\text { Miscellaneous }\end{array}$ & $\begin{array}{l}n=3 \\
n=6 \\
n=2 \\
n=2 \\
n=1\end{array}$ & $\begin{array}{l}n=2 \\
n=1 \\
n=1 \\
n=1 \\
n=1\end{array}$ & $n=1$ \\
\hline Grade 3 & Urosepsis & & $n=1$ & \\
\hline Grade 4 & None & & & \\
\hline Grade 5 & None & & & \\
\hline
\end{tabular}

more electrodes may cause more urinary complaints than using fewer electrodes. In the focal ablation group, the maximal flow decreased significantly, but in the extended group more patients needed an indwelling catheter during the first week after treatment. This could have been supportive in blocking the swelling of the prostate posttreatment.

The aim of focal therapy is to offer Pca patients reliable oncological control whilst preserving their quality of life. To achieve both cancer control and limited treatment-related morbidity, it is of utmost importance to treat the accurate patient population. Recent years, several multidisciplinary consensus projects have established criteria for selection of candidates for focal therapy in prostate cancer [2326]. Furthermore, it is essential to select the most appropriate ablative energy source $[27,28]$. The various options for minimally invasive tissue ablation have different technical characteristics that can be advantageous or disadvantageous depending on the individual patient's clinical situation. The two most frequently used techniques are highintensity focused ultrasound (HIFU) and cryotherapy. An overview for these techniques of post-treatment complications, functional outcomes and quality of life assessment is shown in Table 6. However, implementation of these treatments in clinical practice has not been preceded by a proper safety study. New surgical innovations require structured evaluation, described in the recommendations of the IDEAL collaboration [29].

The phase I-II study is limited by the small cohort size and short follow-up period. But in this period, the results seem encouraging. Though, a successive powered (randomized) study is necessary to confirm these outcomes. Another limitation is that some questionnaires were filled in shortly before the hospital admission for the IRE procedure, which could have led to emotional bias. However, we perceive the results to be promising in comparison with the results of the more mature ablation therapies as HIFU and cryoablation $[30,31]$. Research into conventional focal ablative therapies in the prostate is very heterogeneous, due to differences in trial protocols, patient number and duration of follow-up. Table 6 provides a structured overview of complications, quality of life and functional outcomes of recent HIFU and cryotherapy trials in prostate cancer. Several studies report serious complications as rectourethral fistulas and urethral strictures $[36,42,43,46,48-50,52]$. Our series did not show any persisting toxicity, however it has to be noted that, at this stage of research, our patient number is considerable lower than in most reported series concerning conventional focal therapies. Our results are in accordance with the initial assessment of safety of IRE treatments performed by Valerio et al. [13]. That study shows the results of 34 patients treated with IRE, where 12 patients had grade 1 and 10 patients had grade 2 complications. No grade 3 adverse events occurred. Functional outcomes, based on physician-reports, showed a preservation of potency of $95 \%$ of the men potent before IRE and all men remained continent after treatment at six months post-IRE.

When comparing IRE with results published in a systematic review of several focal techniques, IRE might be beneficial in terms of adverse events and functional outcomes. The overall OR- and procedural time is clearly shorter compared to other FT, which is advantageous in terms of healthcare costs. However, a multicentre randomized controlled trial with larger patient numbers is necessary to confirm the low-morbidity rates. Recently, the Clinical Research Office of the Endourological Society (CROES) has launched a RCT on IRE (comparing two ablation protocols) in which eight European centers will participate to assess both safety and efficacy. Additionally, an international web- 
Citation: Bos WVden, Bruin DMD, Veelo DP, Postema AW, Muller BG, et al. (2015) Quality of Life and Safety Outcomes Following Irreversible Electroporation Treatment for Prostate Cancer: Results from a Phase I-li Study. J Cancer Sci Ther 7: 312-321. doi:10.4172/19485956.1000369
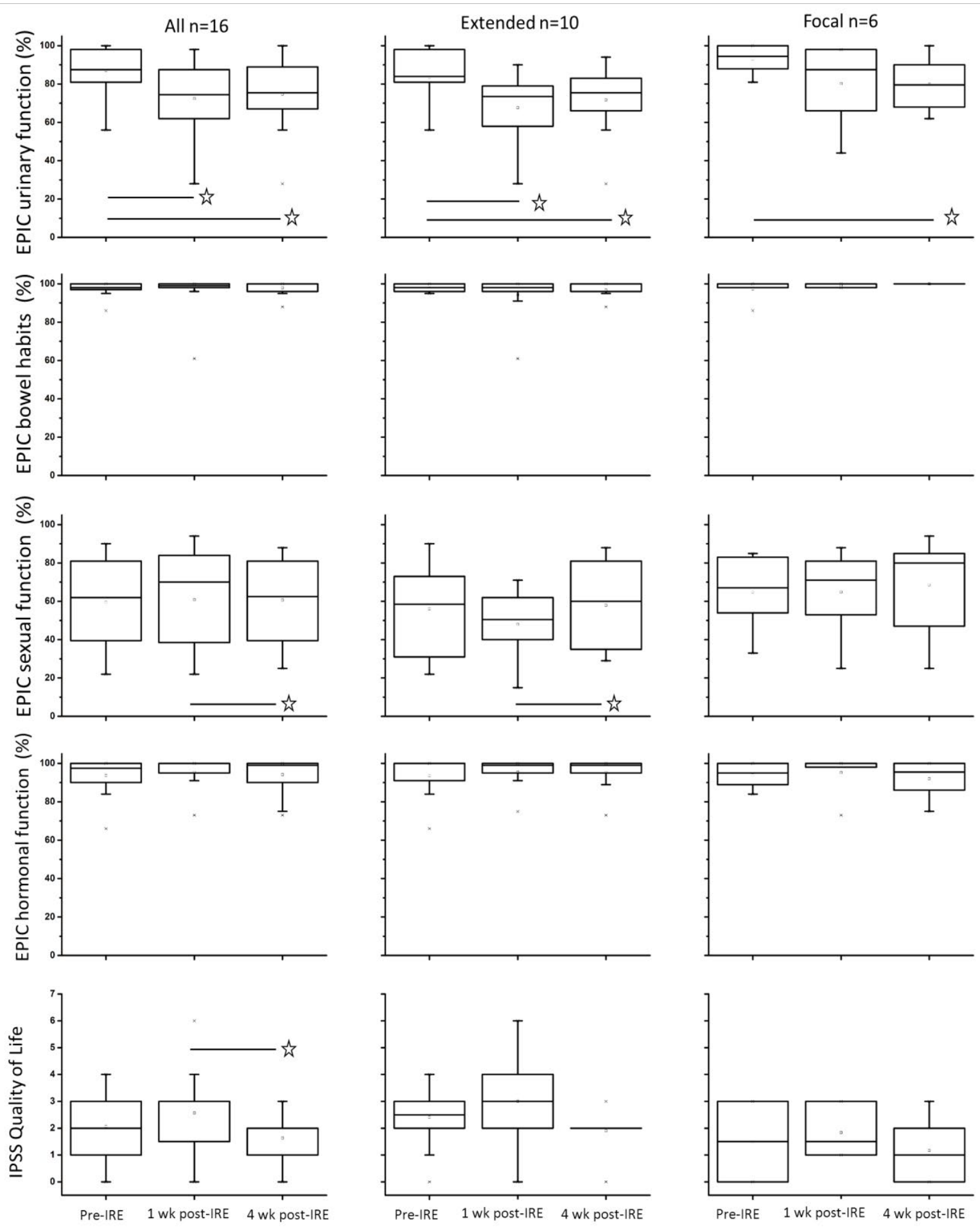

Figure 1: Quality of life outcomes by EPIC per domain and IPSS quality of life score. Significant differences are identified with a star.

based registry database has been designed to address the clinical data associated with IRE in prostate cancers [30].

Since focal treatment is still considered investigational and outof-field disease following FT may occur, it is essential that any focal therapy modality does not compromise the efficacy of salvage therapy, if needed. In all cases, surgery was feasible and the experienced surgeons who performed the RPs did not notice abnormalities or difficulties. No rectal injuries nor rectal fistulae were observed during the surgery itself and postoperatively. However, it is known from the literature that salvage radical prostatectomy for radiation-recurrent disease causes significant deterioration of quality of life in terms of sexual and urinary 
Citation: Bos WVden, Bruin DMD, Veelo DP, Postema AW, Muller BG, et al. (2015) Quality of Life and Safety Outcomes Following Irreversible Electroporation Treatment for Prostate Cancer: Results from a Phase I-li Study. J Cancer Sci Ther 7: 312-321. doi:10.4172/19485956.1000369
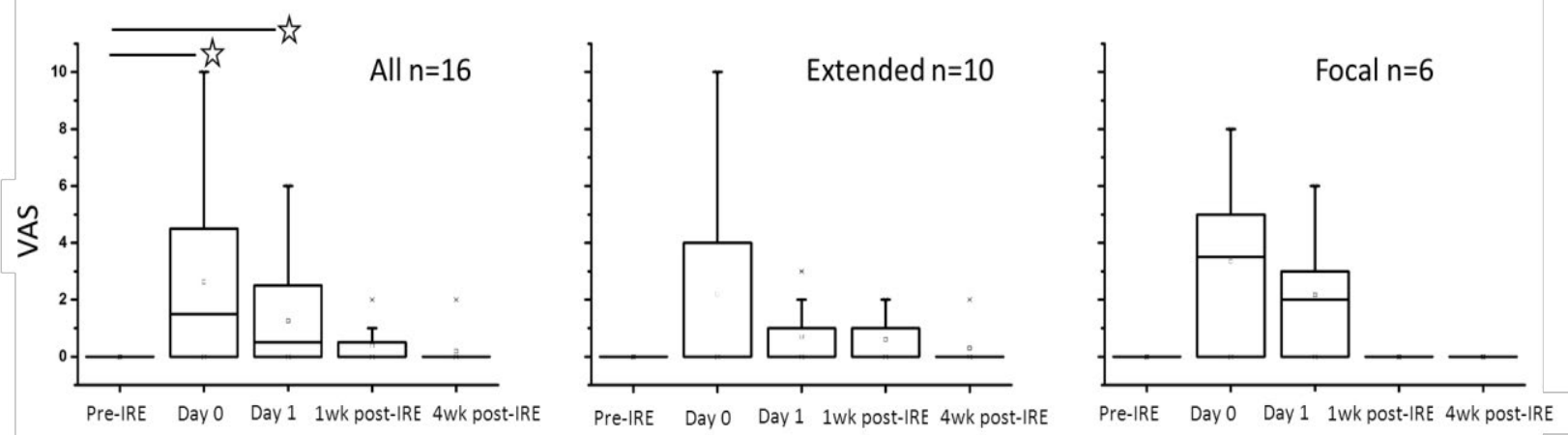

Figure 2: Pain scores pre-IRE and at different time points post-IRE. Significant different outcomes are identified with a star.
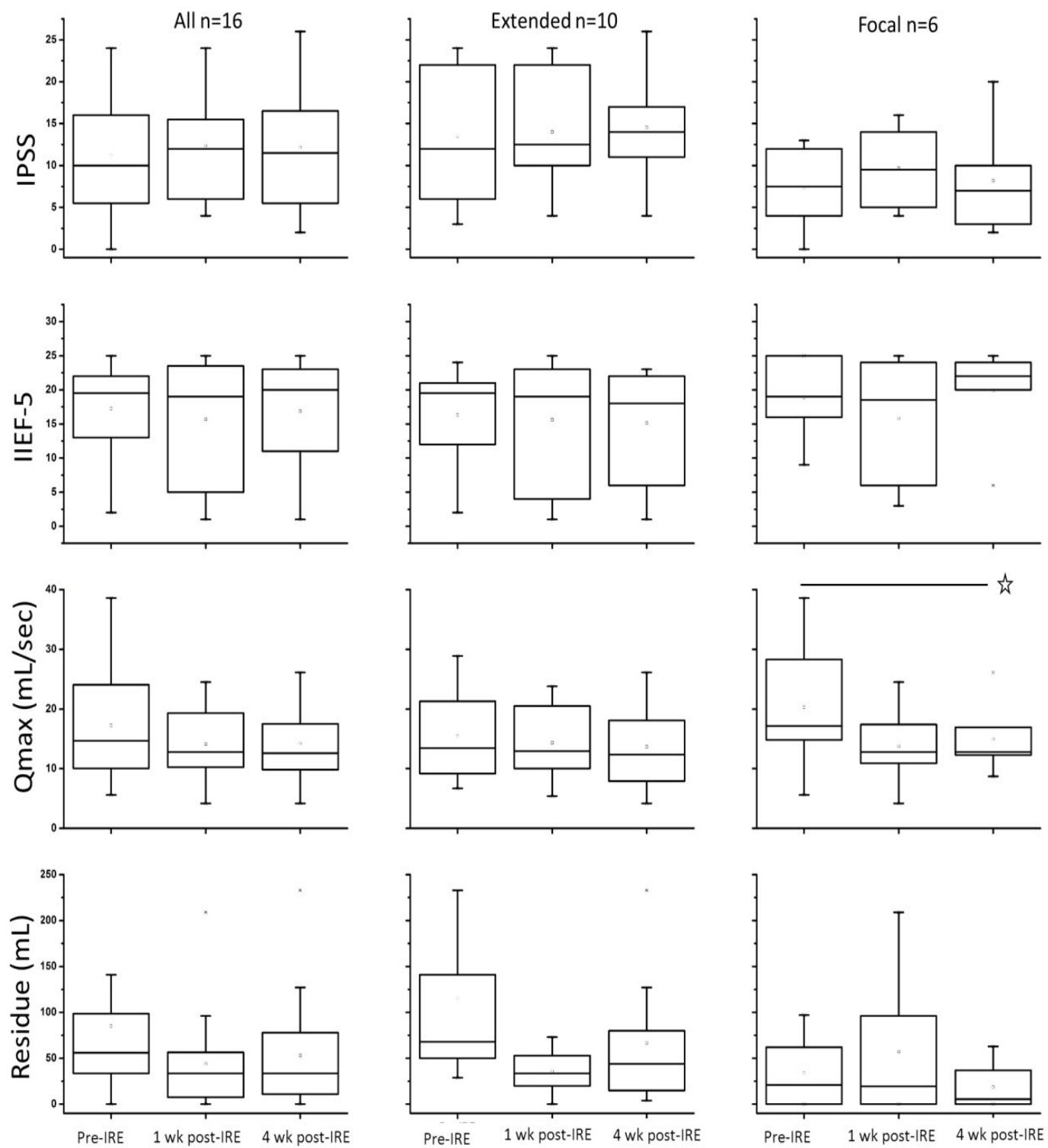

Figure 3: IPSS, IIEF, uroflowmetry (Qmax) and residuals after voiding assessed at baseline, one and four weeks after IRE procedure. Significant differences are identified with a star. 
Citation: Bos WVden, Bruin DMD, Veelo DP, Postema AW, Muller BG, et al. (2015) Quality of Life and Safety Outcomes Following Irreversible Electroporation Treatment for Prostate Cancer: Results from a Phase I-li Study. J Cancer Sci Ther 7: 312-321. doi:10.4172/19485956.1000369

\begin{tabular}{|c|c|c|c|c|}
\hline 1.All & Pre-IRE vs 1 week post & Pre-IRE vs 4 weeks post & \multicolumn{2}{|c|}{1 week - vs 4 weeks post } \\
\hline EPIC uro & $0.01^{*}$ & $0.01^{*}$ & \multicolumn{2}{|c|}{0.86} \\
\hline EPIC bowel & 0.72 & 0.57 & \multicolumn{2}{|r|}{0.43} \\
\hline EPIC sex & 0.54 & 0.17 & \multicolumn{2}{|r|}{$0.03^{*}$} \\
\hline EPIC hor & 0.31 & 0.65 & \multicolumn{2}{|r|}{0.39} \\
\hline IPSS QoL & 0.14 & 0.19 & \multicolumn{2}{|c|}{$0.02^{*}$} \\
\hline IPSS & 0.37 & 0.53 & \multicolumn{2}{|c|}{0.75} \\
\hline IIEF & 0.71 & 1.00 & \multicolumn{2}{|r|}{0.95} \\
\hline Qmax & 0.11 & 0.05 & \multicolumn{2}{|r|}{0.28} \\
\hline Residu & 0.11 & 0.13 & \multicolumn{2}{|r|}{0.66} \\
\hline 2. Extended & Pre-IRE vs 1 week post & Pre-IRE vs 4 weeks post & \multicolumn{2}{|c|}{1 week- vs 4 weeks post } \\
\hline EPIC uro & $0.02^{*}$ & $0.04^{*}$ & \multicolumn{2}{|c|}{0.37} \\
\hline EPIC bowel & 0.87 & 0.83 & \multicolumn{2}{|r|}{0.67} \\
\hline EPIC sex & 0.17 & 0.44 & \multicolumn{2}{|r|}{$0.03^{*}$} \\
\hline EPIC hor & 0.25 & 0.21 & \multicolumn{2}{|r|}{0.71} \\
\hline IPSS QoL & 0.26 & 0.30 & \multicolumn{2}{|r|}{0.08} \\
\hline IPSS & 0.55 & 0.48 & \multicolumn{2}{|r|}{0.39} \\
\hline IIEF & 0.80 & 0.61 & \multicolumn{2}{|r|}{0.28} \\
\hline Qmax & 0.67 & 0.21 & \multicolumn{2}{|r|}{0.67} \\
\hline Residu & 0.07 & 0.16 & \multicolumn{2}{|r|}{0.14} \\
\hline 3. Focal & Pre-IRE vs 1 week post & Pre-IRE vs 4 weeks post & \multicolumn{2}{|c|}{1 week- vs 4 weeks post } \\
\hline EPIC uro & 0.17 & 0.08 & \multicolumn{2}{|c|}{0.46} \\
\hline EPIC bowel & 0.65 & 0.18 & \multicolumn{2}{|r|}{0.16} \\
\hline EPIC sex & 0.75 & 0.35 & \multicolumn{2}{|r|}{0.79} \\
\hline EPIC hor & 0.58 & 0.47 & \multicolumn{2}{|r|}{0.46} \\
\hline IPSS QoL & 0.16 & 0.40 & \multicolumn{2}{|r|}{0.10} \\
\hline IPSS & 0.50 & 0.90 & \multicolumn{2}{|r|}{0.60} \\
\hline IIEF & 0.89 & 0.34 & \multicolumn{2}{|r|}{0.20} \\
\hline Qmax & 0.05 & $0.01^{*}$ & \multicolumn{2}{|r|}{0.10} \\
\hline Residu & 0.70 & 1.00 & \multicolumn{2}{|r|}{0.29} \\
\hline & Pre-IRE vs day 0 & Pre-IRE vs 1 day & Pre-IRE vs 1 week & Pre-IRE vs 4 week \\
\hline VAS All & $0.01^{*}$ & $0.01^{*}$ & 0.06 & 0.18 \\
\hline VAS Focal & 0.07 & 0.07 & 1.00 & 1.00 \\
\hline VAS Extended & 0.07 & 0.07 & 0.06 & 0.18 \\
\hline
\end{tabular}

Table 5: P-values of Wilcoxon signed rank-test for all patients (1), extended treatment group (2), focal treatment group (3).

\begin{tabular}{|c|c|c|c|c|c|c|}
\hline & FT & Complications & Urinary continence & Erectile function & Rectal toxicity & Quality of life \\
\hline Beerlage et al. [32] & HIFU & NR & NR & NR & $\begin{array}{l}\text { Rectourethral fistula 0/14 (0\%) } \\
\text { Perineal pain } 14 / 14(100 \%)\end{array}$ & NR \\
\hline Bahn et al. [33] & Cryo & NR & $28 / 28(100 \%)$ & $24 / 27(88.8 \%)$ & NR & NR \\
\hline Onik et al. [34] & Cryo & NR & $24 / 25(96 \%)$ & $44 / 51(85 \%)$ & NR & NR \\
\hline Ellis et al. [35] & Cryo & NR & $54 / 55(96.4 \%)$ & $24 / 34(70.6 \%)$ & Rectourethral fistula 0/34 (0\%) & \\
\hline Muto et al. [36] & HIFU & Urethral stricture 1/25 (4\%) & NR & NR & NR & NR \\
\hline Robinson et al. [37] & Cryo & NR & NR & $27 / 122(22 \%)$ & NR & $\begin{array}{l}\text { Temporary } \\
\text { deterioration } \\
\text { of urinary } \\
\text { function and } \\
\text { bowel function. } \\
\text { Permanent } \\
\text { deterioration of } \\
\text { sexual function. }\end{array}$ \\
\hline Truesdale et al. [38] & Cryo & NR & $77 / 77(100 \%)$ & NR & NR & NR \\
\hline Li et al. [39] & $\begin{array}{l}\text { HIFU and } \\
\text { cryo }\end{array}$ & NR & NR & $\begin{array}{l}\text { Cryo: } 22 / 47(46.8 \%) \\
\text { HIFU: } 36 / 55(65.5 \%)\end{array}$ & NR & NR \\
\hline El Fegoun et al. [40] & HIFU & $\begin{array}{l}\text { Urinary retention } 1 / 12(8 \%) \\
\text { Urinary tract infection } 2 / 12(16 \%)\end{array}$ & $12 / 12(100 \%)$ & NR & NR & NR \\
\hline
\end{tabular}


Citation: Bos WVden, Bruin DMD, Veelo DP, Postema AW, Muller BG, et al. (2015) Quality of Life and Safety Outcomes Following Irreversible Electroporation Treatment for Prostate Cancer: Results from a Phase I-li Study. J Cancer Sci Ther 7: 312-321. doi:10.4172/19485956.1000369

\begin{tabular}{|c|c|c|c|c|c|c|}
\hline Donnelly et al. [41] & Cryo & $\begin{array}{l}\text { Genitourinary: } \\
\text { - Urgency/frequency } 76 / 117 \\
(64 \%) \\
\text { - Retention } 26 / 117(22 \%) \\
\text { - Pain } 3 / 117(2.6 \%) \\
\text { Diarrhea } 8 / 117(6.8 \%) \\
\text { Fecal incontinence } 9 / 117(7.7 \%) \\
\text { Proctitis } 2 / 117(1.7 \%) \\
\text { Gastrointestinal pain } 17 / 117 \\
(14.5 \%) \\
\text { Gastrointestinal bleeding } 9 / 117 \\
(7.7 \%)\end{array}$ & 79/117 (67.5\%) & $14 / 48(29.1 \%)$ & NR & NR \\
\hline Ahmed et al. [42] & HIFU & Urinary stricture 1/20 (5\%) & $18 / 20(90 \%)$ & $19 / 20(95 \%)$ & - & $\begin{array}{l}\text { No. significant } \\
\text { difference }\end{array}$ \\
\hline Ward et al. [43] & Cryo & Urinary retention 6/518 (1.1\%) & $499 / 507(98.4 \%)$ & $169 / 291(58.1 \%)$ & Rectourethral fistula 1/507 (0.1\%) & NR \\
\hline Bahn et al. [44] & Cryo & NR & $100 \%$ & $36 / 42(86 \%)$ & Rectourethral fistula 0/73 (0\%) & NR \\
\hline Ahmed et al. [45] & HIFU & Urinary retention $1 / 41(2.4 \%)$ & $100 \%$ & $31 / 35(86 \%)$ & $\begin{array}{l}\text { Suspicion of rectourethral fistula } \\
1 / 41(2.4 \%)\end{array}$ & $\begin{array}{l}\text { Significant } \\
\text { deterioration }\end{array}$ \\
\hline Barret et al. [46] & $\begin{array}{l}\text { HIFU and } \\
\text { cryo }\end{array}$ & $\begin{array}{l}\text { Urinary retention 9/106 }(8.5 \%) \\
\text { Pelvic pain } 1 / 106 \\
\text { Gross hematuria } 1 / 106(1 \%) \\
\text { Urethral stricture 1/106 (1\%) }\end{array}$ & $100 \%$ & NR & $\begin{array}{l}\text { Rectourethral fistula with perineal } \\
\text { abscess } 1 / 106(1 \%)\end{array}$ & NR \\
\hline Napoli et al. [47] & HIFU & NR & $3 / 5(60 \%)$ & NR & NR & NR \\
\hline Crouzet et al. [48] & HIFU & $\begin{array}{l}\text { Urinary tract infection } 39 / 1002 \\
(3.9 \%) \\
\text { Urinary retention } 76 / 1002(7.6 \%) \\
\text { Bladder outlet obstruction } \\
166 / 1002(16.6 \%) \\
\text { Hematuria } 55 / 1002(5.5 \%) \\
\text { Stenosis } 90 / 1002(95)\end{array}$ & $765 / 1002(76 \%)$ & $79 / 187(42.3 \%)$ & $\begin{array}{l}\text { Rectourethral fistula } 4 / 1002 \\
(0.4 \%)\end{array}$ & NR \\
\hline Durand et al. [49] & Cryo & $\begin{array}{l}\text { Urinary retention } 7 / 48(15 \%) \\
\text { Cavernous corpus necrosis } 1 / 48 \\
(2 \%) \\
\text { Urethral stenosis } 1 / 48(2 \%)\end{array}$ & $100 \%$ & $\begin{array}{l}\text { No sign. difference } \\
\text { of IIEF }\end{array}$ & Perineal fistula 1/48 (2\%) & NR \\
\hline Mendez [50] & Cryo & Urinary retention $7.3 \%$ & $613 / 62099 \%$ & 193/332 (57.8\%) & Rectourethral fistula $2 / 634(0.3 \%)$ & \\
\hline Barqawi et al. [51] & Cryo & No severe complications & $100 \%$ & $100 \%$ & Rectourethral fistula 0/62 (0\%) & $\begin{array}{l}1.5 \text { point } \\
\text { decrease of } \\
\text { American } \\
\text { Urological } \\
\text { Association } \\
\text { Symptom score }\end{array}$ \\
\hline Ahmed et al. [52] & HIFU & $\begin{array}{l}\text { Dysuria } 9 / 56(16.1 \%) \\
\text { Hematuria } 36 / 56(64.3 \%) \\
\text { Urinary debris } 2 / 56(42.9 \%) \\
\text { Urinary tract infection } 10 / 56 \\
(17.9 \%) \\
\text { Urethral stricture } 2 / 56(3.6 \%)\end{array}$ & $46 / 50(92.0 \%)$ & $30 / 39(76.9 \%)$ & NR & $\begin{array}{l}\text { Very little impact } \\
\text { of health-related } \\
\text { quality of life }\end{array}$ \\
\hline
\end{tabular}

Table 6: Complications and functional outcomes of HIFU and cryotherapy trials.

dysfunction [31]. Although the functional outcomes following the post-IRE radical prostatectomy were beyond the scope of this study, it is very well possible that patients may experience more surgical-related morbidity due to the prior IRE.

\section{Conclusion}

IRE ablations can be performed safely in patients suffering from prostate cancer. The adverse events are mostly temporary and mainly grade 1 and 2 side effects are observed. Quality of life assessment shows deterioration in the urinary domain in both treatment protocols, however functional outcomes remain stable over time.

\section{References}

1. Siegel R, Ma J, Zou Z, Jemal A (2014) Cancer statistics, 2014. CA Cancer J Clin 64: 9-29.

2. Bartsch G, Horninger W, Klocker H, Pelzer A, Bektic J, et al. (2008) Tyrol Prostate Cancer Demonstration Project: early detection, treatment, outcome, incidence and mortality. BJU Int 101: 809-816.
3. Cooperberg MR, Lubeck DP, Mehta SS, Carroll PR; CaPSURE (2003) Time trends in clinical risk stratification for prostate cancer: implications for outcomes (data from CaPSURE). J Urol 170: S21-25.

4. Weir HK, Thompson TD, Soman A, Møller B3, Leadbetter S1 (2015) The past, present, and future of cancer incidence in the United States: 1975 through 2020. Cancer 121: 1827-1837.

5. Gulati R, Wever EM, Tsodikov A, Penson DF, Inoue LY, et al. (2011) What if I don't treat my PSA-detected prostate cancer? Answers from three natural history models. Cancer Epidemiol Biomarkers Prev 20: 740-750.

6. Latini DM, Hart SL, Knight SJ, Cowan JE, Ross PL, et al. (2007) The relationship between anxiety and time to treatment for patients with prostate cancer on surveillance. J Urol 178: 826-831.

7. Mazur DJ, Hickam DH, Mazur MD (1999) How patients' preferences for risk information influence treatment choice in a case of high risk and high therapeutic uncertainty: asymptomatic localized prostate cancer. Med Decis Making 19: 394-398.

8. Eggener S (2014) Commentary on: "Long-term functional outcomes after treatment for localized prostate cancer." Resnick MJ, Koyama T, Fan KH, Albertsen PC, Goodman M, Hamilton AS, Hoffman RM, Potosky AL, Stanford JL, Stroup AM, Van Horn RL, Penson DF. Department of Urologic Surgery 
Citation: Bos WVden, Bruin DMD, Veelo DP, Postema AW, Muller BG, et al. (2015) Quality of Life and Safety Outcomes Following Irreversible Electroporation Treatment for Prostate Cancer: Results from a Phase I-li Study. J Cancer Sci Ther 7: 312-321. doi:10.4172/19485956.1000369

and the Center for Surgical Quality and Outcomes Research, Vanderbilt University, Nashville, TN.: N Engl J Med 2013;368(5):436-45. doi: 10.1056/ NEJMoa1209978. Urol Oncol 32: 513-514.

9. Novara G, Ficarra V, Mocellin S, Ahlering TE, Carroll PR, et al. (2012) Systematic review and meta-analysis of studies reporting oncologic outcome after robot-assisted radical prostatectomy. Eur Urol 62: 382-404.

10. Ficarra V, Novara G, Rosen RC (2012) Systematic review and meta-analysis of studies reporting urinary continence recovery after robot-assisted radical prostatectomy. Eur Urol 2012;62: 405-417.

11. Valerio M, Ahmed HU, Emberton M, Lawrentschuk N, Lazzeri M, et al. (2014) The role of focal therapy in the management of localised prostate cancer: a systematic review. Eur Urol 66: 732-751.

12. Onik G, Mikus $P$, Rubinsky B (2007) Irreversible electroporation: implications for prostate ablation. Technol Cancer Res Treat 6: 295-300.

13. Valerio M, Stricker PD, Ahmed HU, Dickinson L, Ponsky L, et al. (2014) Initia assessment of safety and clinical feasibility of irreversible electroporation in the focal treatment of prostate cancer. Prostate Cancer Prostatic Dis 17: 343-347.

14. Scheffer HJ, Nielsen K, de Jong MC, van Tilborg AA, Vieveen JM, et al. (2014) Irreversible electroporation for nonthermal tumor ablation in the clinical setting: a systematic review of safety and efficacy. J Vasc Interv Radiol 25: 997-1011.

15. Van den Bos W, de Bruin DM, Muller BG, Varkarakis IM, Karagiannis AA, et al. (2014) The safety and efficacy of irreversible electroporation for the ablation of prostate cancer: a multicentre prospective human in vivo pilot study protocol. BMJ Open 4: e006382.

16. Wei JT, Dunn RL, Litwin MS, Sandler HM, Sanda MG (2000) Development and validation of the expanded prostate cancer index composite (EPIC) for comprehensive assessment of health-related quality of life in men with prostate cancer. Urology 56: 899-905

17. Rosen RC, Althof SE, Giuliano F (2006) Research instruments for the diagnosis and treatment of patients with erectile dysfunction. Urology 68: 6-16.

18. Lee EW, Wong D, Prikhodko SV, Perez A, Tran C, et al. (2012) Electron microscopic demonstration and evaluation of irreversible electroporation-induced nanopores on hepatocyte membranes. J Vasc Interv Radiol 23: 107-113.

19. Chang DC, Reese TS (1990) Changes in membrane structure induced by electroporation as revealed by rapid-freezing electron microscopy. Biophys J 58: 1-12

20. Al-Sakere B, André F, Bernat C (2007) Tumor ablation with irreversible electroporation. PLOS One 2:8.

21. Olweny EO, Kapur P, Tan YK, Park SK, Adibi M, et al. (2013) Irreversible electroporation: evaluation of nonthermal and thermal ablative capabilities in the porcine kidney. Urology 81: 679-684.

22. Pech M, Janitzky A, Wendler JJ, Strang C, Blaschke S, et al. (2011) Irreversible electroporation of renal cell carcinoma: a first-in-man phase I clinical study. Cardiovasc Intervent Radiol 34: 132-138.

23. Donaldson IA, Alonzi R, Barratt D, Barret E, Berge V, et al. (2015) Foca therapy: patients, interventions, and outcomes--a report from a consensus meeting. Eur Urol 67: 771-777.

24. van den Bos W, Muller BG, Ahmed H, Bangma CH, Barret E, et al. (2014) Focal therapy in prostate cancer: international multidisciplinary consensus on trial design. Eur Urol 65: 1078-1083.

25. De la Rosette J, Ahmed H, Barentsz J, Johansen TB, Brausi M, et al. (2010) Focal therapy in prostate cancer-report from a consensus panel. J Endourol 24: $775-780$

26. Jayram G, Eggener SE (2009) Patient selection for focal therapy of localized prostate cancer. Curr Opin Urol 19: 268-273.

27. Coleman JA, Scardino PT (2013) Targeted prostate cancer ablation: energy options. Curr Opin Urol 23: 123-128.

28. Van den Bos W, de Bruin DM, Jurhill RR, Savci-Heijink CD, Muller BG, et al. (2015) The correlation between the electrode configuration and histopathology of irreversible electroporation ablations in prostate cancer patients. World J Urol.

29. McCulloch P, Altman DG, Campbell WB, Flum DR, Glasziou P, et al. (2009) No surgical innovation without evaluation: the IDEAL recommendations. Lancet 374: $1105-1112$
30. Van den Bos W, de la Rosette J (2015) Randomized controlled trial on irreversible electroporation for localized prostate cancer:focal ablation versus extended ablation. J Endourol 29: 851-854.

31. Chade DC, Eastham J, Graefen M, Hu JC, Karnes RJ, et al. (2012) Cance control and functional outcomes of salvage radical prostatectomy for radiationrecurrent prostate cancer: a systematic review of the literature. Eur Urol 61 : 961-971.

32. Beerlage HP, van Leenders GJ, Oosterhof GO, Witjes JA, Ruijter ET, et at. (1999) High-intensity focused ultrasound (HIFU) followed after one to two weeks by radical retropubic prostatectomy: results of a prospective study Prostate 39: 41-46.

33. Bahn DK, Silverman $P$, Lee F Sr, Badalament R, Bahn ED, et al. (2006) Focal prostate cryoablation: initial results show cancer control and potency preservation. J Endourol 20: 688-692.

34. Onik G, Vaughan D, Lotenfoe R (2007) 'Male lumpectomy': focal therapy for prostate cancer using cryoablation. Urology 2007;70: 16-21.

35. Ellis DS, Manny TB Jr, Rewcastle JC (2007) Cryoablation as primary treatment fo localized prostate cancer followed by penile rehabilitation. Urology 69: 306-310.

36. Muto S, Yoshii T, Saito K, Kamiyama Y, Ide H, et al. (2008) Focal therapy with high-intensity-focused ultrasound in the treatment of localized prostate cancer. Jpn J Clin Oncol 38: 192-199.

37. Robinson JW, Donnelly BJ, Siever JE, Saliken JC, Ernst SD, et al. (2009) A randomized trial of external beam radiotherapy versus cryoablation in patients with localized prostate cancer: quality of life outcomes. Cancer 115: 4695-4704.

38. Truesdale MD, Cheetham PJ, Hruby GW, Wenske S, Conforto AK, et al (2010) An evaluation of patient selection criteria on predicting progression-free survival after primary focal unilateral nerve-sparing cryoablation for prostate cancer: recommendations for follow up. Cancer J 16: 544-549.

39. Li LY, Lin Z, Yang M, Gao X, Xia TL, et al. (2010) Comparison of penile size and erectile function after high-intensity focused ultrasound and targeted cryoablation for localized prostate cancer: a prospective pilot study. J Sex Med 7: 3135-3142.

40. El Fegoun AB, Barret E, Prapotnich D, Soon S, Cathelineau X, et al. (2011) Focal therapy with high-intensity focused ultrasound for prostate cancer in the elderly. A feasibility study with 10 years follow-up. Int Braz J Urol 37: 213-219.

41. Donnelly BJ, Saliken JC, Brasher PM, Ernst SD, Rewcastle JC, et al. (2010) A randomized trial of external beam radiotherapy versus cryoablation in patients with localized prostate cancer. Cancer 116: 323-330.

42. Ahmed HU, Freeman A, Kirkham A (2011) Focal therapy for localized prostate cancer: a phase I/II trial. J Urol 185:1246-1254.

43. Ward JF, Jones JS (2012) Focal cryotherapy for localized prostate cancer: report from the national Cryo On-Line Database (COLD) Registry. BJU Int 109: $1648-1654$

44. Bahn D, de Castro Abreu AL, Gill IS, Hung AJ, Silverman P, et al. (2012) Focal cryotherapy for clinically unilateral, low-intermediate risk prostate cancer in 73 men with a median follow-up of 3.7 years. Eur Urol 62: 55-63.

45. Ahmed HU, Hindley RG, Dickinson L, Freeman A, Kirkham AP, et al. (2012) Focal therapy for localised unifocal and multifocal prostate cancer: a prospective development study. Lancet Oncol 13: 622-632.

46. Barret E, Ahallal Y, Sanchez-Salas R, Galiano M, Cosset JM, et al. (2013) Morbidity of focal therapy in the treatment of localized prostate cancer. Eur Urol 63: 618-622.

47. Napoli A, Anzidei M, De Nunzio C, Cartocci G, Panebianco V, et al. (2013) Realtime magnetic resonance-guided high-intensity focused ultrasound focal therapy for localised prostate cancer: preliminary experience. Eur Urol 63: 395-398.

48. Crouzet S, Chapelon JY, Rouvière O, Mege-Lechevallier F, Colombel M, et al. (2014) Whole-gland ablation of localized prostate cancer with high-intensity focused ultrasound: oncologic outcomes and morbidity in 1002 patients. Eur Urol 65: 907-914.

49. Durand M, Barret E, Galiano M, Rozet F, Sanchez-Salas R, et al (2014) Focal cryoablation: a treatment option for unilateral low-risk prostate cancer. BJU Int 113: 56-64.

50. Mendez MH, Passoni NM, Pow-Sang J, Jones JS, Polascik TJ (2015) Comparison of Outcomes Between Preoperatively Potent Men Treated with 
Citation: Bos WVden, Bruin DMD, Veelo DP, Postema AW, Muller BG, et al. (2015) Quality of Life and Safety Outcomes Following Irreversible Electroporation Treatment for Prostate Cancer: Results from a Phase I-li Study. J Cancer Sci Ther 7: 312-321. doi:10.4172/19485956.1000369

Focal Versus Whole Gland Cryotherapy in a Matched Population. J Endourol 29: 1193-1198.

51. Barqawi AB, Stoimenova D, Krughoff K, Eid K, O'Donnell C, et al. (2014) Targeted focal therapy for the management of organ confined prostate cancer.

\section{J Urol 192: 749-753}

52. Ahmed HU, Dickinson L, Charman S, Weir S, McCartan N, et al. (2015) Focal Ablation Targeted to the Index Lesion in Multifocal Localised Prostate Cancer: a Prospective Development Study. Eur Urol. 